\title{
ANALISIS PENGARUH TEMPERATUR TERHADAP LUBKRIKASI PADA MOULD DAN KUALITAS WHEEL PADA PROSES DIE CASTING
}

\author{
AHMAD ISKANDAR ${ }^{1}$, AMIR $^{2}$, AMRULLAH $^{3}$ \\ Program Studi Teknik Mesin, Fakultas Teknik, Universitas Muhammadiyah Tangerang \\ Jl. Perintis Kemerdekaan I/33 Cikokol-Tangerang \\ E-Mail : iskandar.umt@yahoo.com
}

\begin{abstract}
ABSTRAK
Pesawat terbang merupakan transportasi yang sangat diminati oleh masyarakat, karena kenyamanan dan waktu penerbangan yang sangat singkat. Pada saat ini penguasaan teknologi rancang bangun di bidang kedirgantaraan sangatlah pesat contohnya saja bermunculan berbagai jenis pesawat terbang seperti Boeing series, Airbus Series, Bombardir Series, ATR Series, bahkan dalam negeri juga mempunyai pesawat tersendiri buatan PT Dirgantara Indonesia seperti CN (235,295,2235-200), NC212, Helikopter H21 Super Puma, N219, dan lain-lain. Aliran udara melewati fan blade pada pesawat terbang jenis BOEING 737-800NG dengan mesin CFM56-7B yang dianalisa menggunakan software CFD. Pada penelitian ini memfokuskan pengaruh ketinggian terhadap kecepatan, gaya dorong, dan gaya hambat pada aliran udara melewati fan blade dengan menggunakan software CFD. Metode yang digunakan dalam penelitian ini, pengumpulan data langsung pada objek yang di analisis pada software CFD. Berdasarkan simulasi pada CFD dapat disimpulkan bahwa Velocity $x$ dan pressure setelah melewati fan blade pada ketinggian 10.000 feet, masing-masing menghasilkan 157,057 $\mathrm{m} / \mathrm{s}$ dan $64801.10 \mathrm{pa}$. Sedangkan berdasarkan ketinggian 20.000 feet, masing-masing menghasilkan 199,797 m/s dan 30619,11 Pa. Pola aliran udara yang dibelakang fan blade menghasilkan pola aliran udara laminar dan gaya dorong (thrust) dan gaya tahanan (drag) yang di hasilkan pada ketinggian 10.000 feet berturut-turut adalah 115120,442 N dan 12244,13N, dan pada ketinggian 20.000 feet adalah 134418,55 $N$ dan 15965,3.
\end{abstract}

Kata Kunci : Die Casting, Wheel, High pressure, Dies/Cetakan

\begin{abstract}
The technology in the Die Casting mold process has been used to make relatively difficult products with Machining processes. In addition, literature reports on the superiority of die casting process technology that proves capable of producing a product at a relatively low price with better quality. The main capital of production process with this route is the die casting process with various methods both mechanically, chemically, and pressure. In this research is focused on Casting Wheel production process by mold method on High pressure die casting process by analyzing a mold temperature to maximize mold lubrication in affect to the quality of a wheel product. Expected results after analyzing this process that can produce a product with the best quality to meet the standards on the process of die casting because the needs of the company to be utilized as increasing productivity in the production process of die casting.
\end{abstract}

Keywords: Die Cating, Wheel, High Pressure, Dies/Mould

\section{PENDAhUluAN}

Saat ini, teknologi berkembang sangatlah pesat dan kemudian di aplikasikan kedalam berbagai macam bidang, termasuk kedalam bidang produksi. Melihat dari hal tersebut, penulis bermaksud untuk menganalisa pengaruh temperatur terhadap lubrikasi di mould dan kualitas produk pada proses die casting.

Maka dari pada itu untuk meningkatkan perkembangan kedalam bidang produksi casting, penulis bermaksud menganalisa pengaruh temperatur lubrikasi dan kualitas produk die casting dengan hasil yang maksimal, sehingga dapat menghasilkan produk yang berkualitas .

Hasil yang diharapkan yaitu dapat menghasilkan produk wheel yang sesuai dan memenuhi standar kualitas yang diinginkan PT. XY, dan hasil analisa ini diperuntukan sebagai media pembelajaran pada bidang produksi die casting/pengecoran,

Kondisi cacat yang paling banyak dijumpai pada proses pengecoran saluran adalah Flowline atau pertemuan aluminium tidak menyatu dan menimbulkan kerutan pada produk. Banyak faktor yang mempengaruhi proses pengecoran ini sehingga menyebabkan cacat tersebut.

Flowline Adalah fenomena cairan aluminium yang mengalir kedalam cetakan tidak dapat menyatu dengan sempurna sehingga menyebabkan kerutan yang dalam pada permukaan produk. 


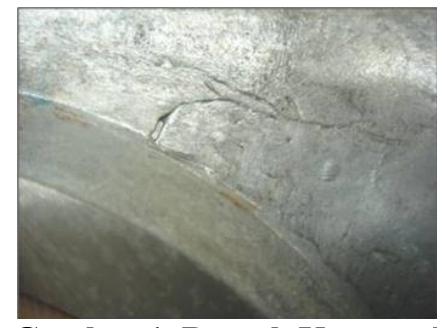

Gambar 1. Bentuk Kerutan Flowline

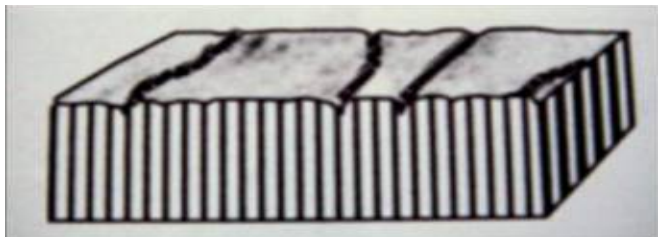

Gambar 2. Bentuk Flowline Bentuk Potongan

Penyebab utama terjadinya flowline karena beberapa hal. Diantaranya adalah spray dari jumlah lubrikasi terlalu banyak, penurunan temperatur mould atau cetakan, point/titik spray lubrikasi tidak tepat, proses gerakan injeksi saat aluminium ditekan masuk menjadi abnormal karena tidak terlubrikasi dan gas ventilasi dari cetakan tidak bagus.

Soldering adalah gejala menempelnya aluminium pada cavity/ cetakan karena pengaruh panas/temperatur pada bagian tertentu saja yang overheat/tidak terkena lubrikasi.

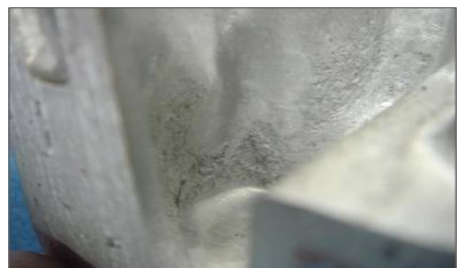

Gambar 3. Bentuk Aluminum yang Hilang dari Produk

Penyebab utama terjadinya soldering yaitu karena pengaruh dari pendinginan external dari lubrikasi yang tidak sempurna. Selain itu, aluminiuim yang menempel pada bagian cetakan yang sudah crack (1:100 kasus).

Fenomena dari terjadinya abnormal mekure adalah pada permukaan produk ada bagian yang terkelupas tipis karena proses machining atau pada saat proses penghilangan burry lebih pada produk.

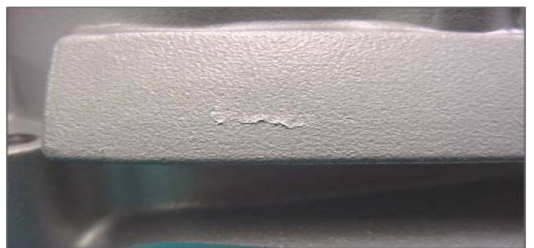

Gambar 4 Bentuk Daging yang Terkelupas dari Produk
Penyebab utama terjadinya mekure pada produk yaitu gas terjebak dari sisa lubrikasi yang terbakar oleh aluminum, proses lubrikasi yang tidak sempurna dan pemilihan material lubrikasi yang tidak bagus

Galling atau dalam bahasa jepang Kajiri adalah kondisi cacat produk yang terjadi akibat pada saat cetakan membuka atau ketika produk release, terjadi scratch pada permukaan produk (seperti cakaran).

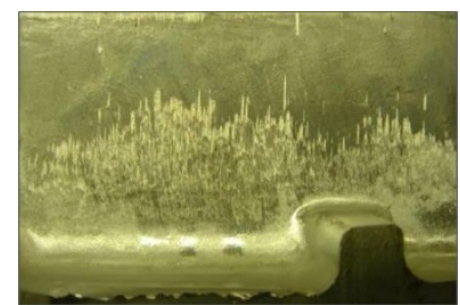

Gambar 5. Bentuk Cacat Produk Galling pada Permukaan

Penyebab utama terjadinya galling diantaranya adalah permukaan bagian yang galling/scratch tidak terlubrikasi, komposisi casiran lubrikasi tidak tepat, draft angle permukaan tidak bagus dan under cut/ permukaan antara produk yang galling terdapat step.

Shringkage adalah fenomena terjadinya ruang kosong yang tidak terisi aluminium pada bagian dalam produk. Atau dalam kata lain terdapat sisa gas yang terjebak pada cetakan yang tidak berhasil keluar.

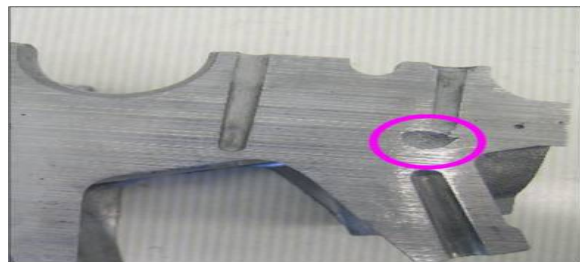

Gambar 6. Bentuk Cacat Produk Shringkage di dalam Produk

Penyebab utama shringkage diantaranya adalah turbulensi dari aluminium yang didorong melebihi kecepatan yang ditentukan oleh perhitungan, shringkage karena gas terjebak (sisa lubrikasi yang terbakar dan menguap berubah menjadi gas).

Retakan pada cetakan atau dalam kata lain heat check Adalah fenomena dimana pada cetakan terdapat gejala-gejala retakan kecil akibat pemuaian dan penyusutan berulang secara terus-menerus yang terdapat pada produk. Hal ini wajar terjadi karena pada saat aluminium masuk temperatur $\pm 620^{\circ} \mathrm{C}$ kemuadian di dinginkan melalui pendinginan internal dan external sehingga suhu cetakan menjadi drop. 


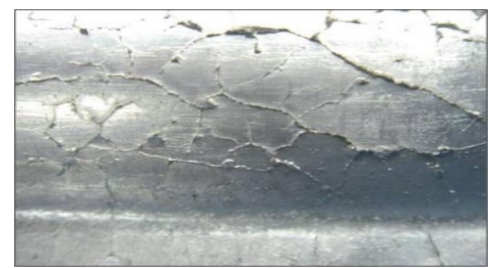

Gambar 7. Bentuk Heat Check Pada Produk

Penyebab terjadinya heat check diantaranya adalah kondisi cetakan sudah termakan usia (life time) dan kekerasan cetakan rendah miss run (Fill up defect).

Miss run adalah fenomena terjadinya solidifikasi pada saat masih ada bagian didalam cetakan yang belum terisi penuh dengan cairan aluminium.

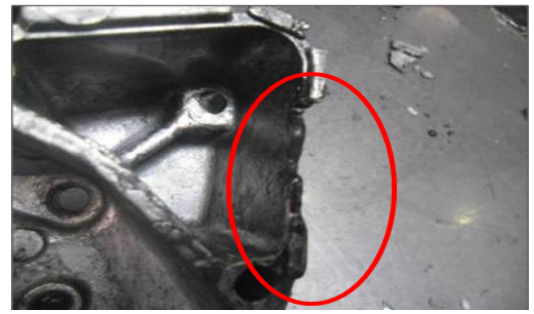

Gambar 8. Bentuk Miss Run pada Produk

Penyebab utama terjadinya Miss run terbagi dalam beberapa hal diantaranya adalah temperatur cetakan menurun/drop dan gas release tidak sempurna

\section{METODOLOGI PENELITIAN}

Proses pengecekan temperatur dimulai dilakukan terlebih dahulu proses simulasi dengan menggunakan alat (Thermotracer/thermogear) untuk mengecek suhu optimal pada cetakan/dies, kemudian di analisa dengan menggunakan software INFRECT, hal ini bertujuan untuk melihat bentuk temperatur yang ada di cetakan yang berbeda, dan hasil dari temperatur ini digunakan untuk kelengkapan tugas akhir. Pada proses ini dilakukan simulasi berdasarkan fungsi dan jenis die lubricant yang dipakai.

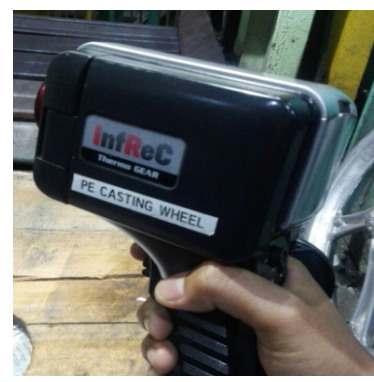

Gambar 9. Thermotracer Jenis Infrec

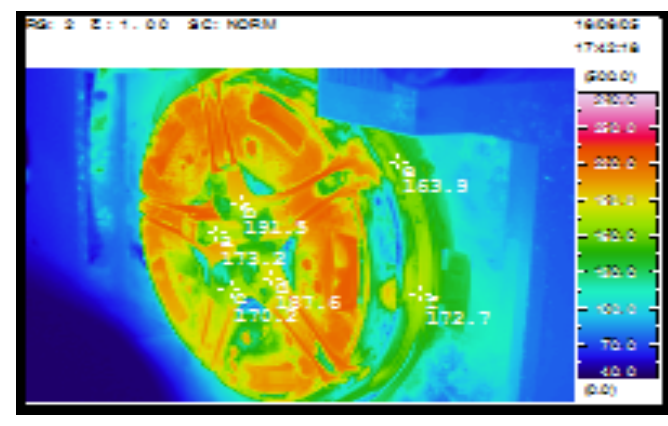

Gambar 10. Temperatur Cetakan

Pengambilan temperatur menggunakan Thermotracer dapat diambil untuk simulasi cetakan pada saat after casting.Dalam Pengetesan Die Lube dilakukan menggunakan pure die lubricant yang di teteskan ke alat heater dan di cek menggunakan pengecekan temperatur dengan thermotracer. Sebelum dilakukan pengetesan/pengecekan die lubricant dibutuhkan alat/bahan sebagai berikut.

Tabel 1. Trial Alat dan Bahan

\begin{tabular}{|l|l|}
\hline \multicolumn{1}{|c|}{ Item Check } & \multicolumn{1}{|c|}{ Satuan/Hasil } \\
\hline Dirution & 100 \\
\hline Material & $\begin{array}{l}\text { SUS304 }(100 \times 10 \\
\text { 0x2,5) }\end{array}$ \\
\hline Temperature $\left({ }^{\circ} \mathrm{C}\right)$ & $\begin{array}{l}120,150,200, \\
250,300,350^{\circ} \mathrm{C}\end{array}$ \\
\hline Spray Timer $(\mathrm{Sec})$ & 1,5 \\
\hline Distance $(\mathrm{mm})$ & 200 \\
\hline Air Pressure $(\mathrm{Mpa})$ & 0,4 \\
\hline $\begin{array}{l}\text { Lubrication pressure } \\
(\text { Mpa })\end{array}$ & 0,1 \\
\hline Nozzle & Atomax \\
\hline
\end{tabular}

Alat untuk mengecek die lubricant pada saat spray time dengan temperatur yang bisa di atur untuk mengetahui bagus atau tidaknya lubricant menempel terhadap cetakan.

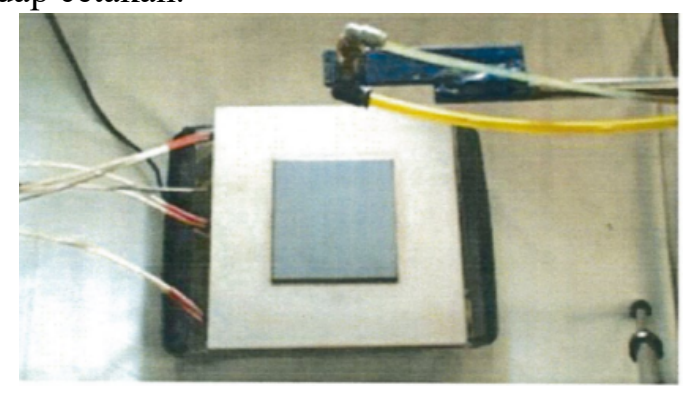

Gambar 11. Alat Uji Die Lubricant 
Standar pengambilan sampel bagus/tidaknya suatu lubricant dibuatkan standar untuk temperatur berapa lubricant bisa menempel.
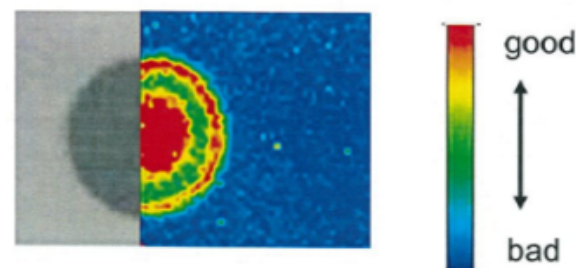

\section{Gambar 12. Standar Die Lubricant Good/No good}

\section{HASIL DAN PEMBAHASAN}

\subsection{Temperatur Optimal Lubricant Die Casting}

Fungsi Die Lubricant pada proses pengecoran logam atau dalam istilah lain yaitu die casting adalah untuk melapisi cetakan agar lapisan film dari die lubricant menempel pada cetakan, sehingga loss time trouble lengket produk pada cetakan dapat di minimalisir. Temperatur cetakan terhadap lubricant yang tepat akan berpengaruh pada mampu lubricant menempel cetakan dengan sempurna yang kemudian mngakibatkan cetakan terlapisi sempurna oleh die lubricant pada proses die casting. Sehingga dibutuhkan temperatur cetakan yang optimal.

Adapun temperatur yang dibutuhkan agar lubricant dapat melumasi cetakan die casting pada suhu target $150-250^{\circ} \mathrm{C}$. karena pada temperatur tersebut lubrikasi akan melapisi cetakan dengan sempurna. Pada data trial yang sudah dilakukan di perusahaan PT. XY sebanyak 6 kali dan didapatkan bahwa:

Peneliti melakukan eksperimen pada perusahaan PT. XY dengan menggunakan mesin berkapasitas 800 Ton yaitu pada jenis / model produk yaitu wheel. Trial dilakukan dengan langkah-langkah sebagai berikut:

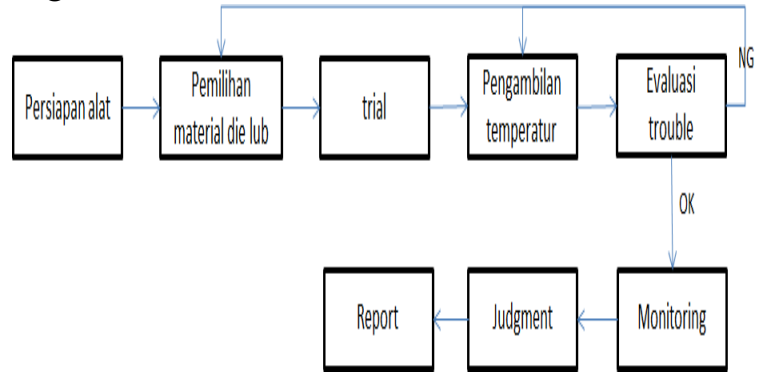

Gambar 14. Langkah-Langkah Trial

Dari data trial yang dilakukan sebanyak 6 kali dapat di lihat bahwa semakin cepat timer cooling maka semakin overheat, tetapi jika terlalu lama pun temperatur semakin dingin.

Tabel 2. Trial Temperatur Dengan Timer

\begin{tabular}{|c|c|c|c|c|}
\hline Phase & Data Trial & $\begin{array}{l}\text { Timer cooling } \\
\text { standar }\end{array}$ & $\begin{array}{c}\text { Data timer } \\
\text { temperatur (sec) }\end{array}$ & $\begin{array}{l}\text { Temperatur } \\
\text { actual|('C) }\end{array}$ \\
\hline \multirow{5}{*}{$\mathrm{T} 1$} & 1 & \multirow{29}{*}{$30-50$ second } & 10 & 315 \\
\hline & 2 & & 12 & 305 \\
\hline & 3 & & 14 & 299 \\
\hline & 4 & & 16 & 294 \\
\hline & 5 & & 18 & 289 \\
\hline \multirow{5}{*}{$\mathrm{T} 2$} & 1 & & 20 & 282 \\
\hline & 2 & & 22 & 275 \\
\hline & 3 & & 24 & 269 \\
\hline & 4 & & 26 & 263 \\
\hline & 5 & & 28 & 258 \\
\hline \multirow{5}{*}{ T3 } & 1 & & 30 & 250 \\
\hline & 2 & & 32 & 235 \\
\hline & 3 & & 34 & 221 \\
\hline & 4 & & 36 & 213 \\
\hline & 5 & & 38 & 201 \\
\hline \multirow{5}{*}{ T4 } & 1 & & 40 & 198 \\
\hline & 2 & & 42 & 189 \\
\hline & 3 & & 44 & 175 \\
\hline & 4 & & 46 & 164 \\
\hline & 5 & & 48 & 157 \\
\hline \multirow{5}{*}{ T5 } & 1 & & 50 & 149 \\
\hline & 2 & & 52 & 135 \\
\hline & 3 & & 54 & 124 \\
\hline & 4 & & 56 & 112 \\
\hline & 5 & & 58 & 103 \\
\hline \multirow{4}{*}{ T6 } & 1 & & 60 & 97 \\
\hline & 2 & & 62 & 93 \\
\hline & 3 & & 64 & 86 \\
\hline & 4 & & 66 & 80 \\
\hline
\end{tabular}

Dari data tabel diatas didapat bahwa dengan semakin cepat waktu alir cooling maka temperatur cetakan semakin overheat yang dapat mengakibatkan defect pada produk dan bisa menimbulkan trouble lengket pula. Sementara jika timer cooling semakin lambat pun mengakibatkan semakin dingin pula cetakan yang mengakibatkan die lubricant tidak akan pernah melapisi pada cetakan.
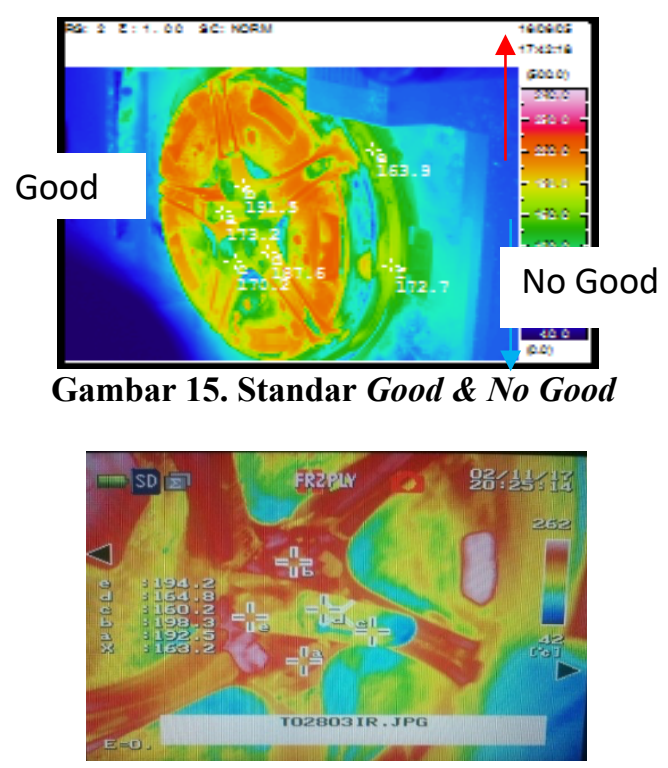

Gambar 16. Temperatur Optimal Cetakan

Temperatur optimal pada pengambilan suhu pada cetakan mould di dapat bahwa dengan 
temperatur yang masuk kedalam range $150-250^{\circ} \mathrm{C}$ tidak mengalami masalah lengket pada cetakan dan kualitas yang dihasilkan pun sangat bagus karena untuk produk yang defect tidak bermasalah.

Sementara temperatur jika $<150^{\circ} \mathrm{C}$ mengalami lengket pada cetakan karena die lubricant tidak dapat melapisi cetakan dengan sempurna. Sama halnya jika kelebihan temperatur jika $>250^{\circ} \mathrm{C}$ juga mengalami defect produk dan trouble lengket pun ada.

Pengambilan temperatur pada cetakan before spray dan atomizer dan kemudian di input menggunakan software infrect di dapat bahwa temperatur optimum die lubricant dapat melapisi cetakan $150^{\circ} \mathrm{C}-250^{\circ} \mathrm{C}$.

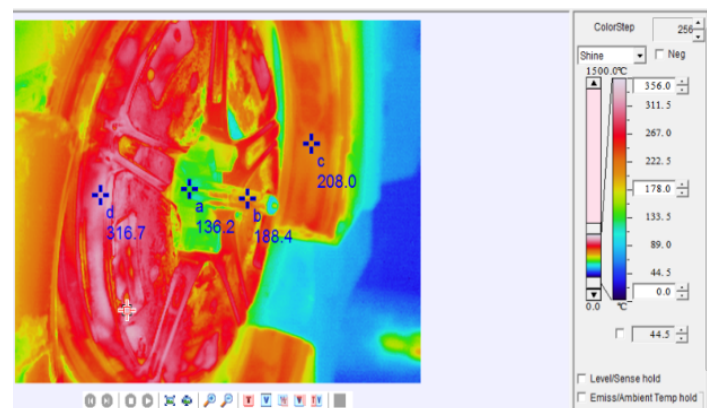

\section{Gambar 17. Software Infrect Data Temperatur}

Bandingkan dengan kualitas pada titik-titik temperatur tersebut mulai dari temperatur yang rendah sampai temperatur maksimum pengaruh temperatur terhadap mampu lubricant melapisi dan hasil kualitas produknya diantaranya:

1. Temperatur (a) menunjukan angka $136^{\circ} \mathrm{C}$ mengakibatkan produk lengket pada cetakan. Hal ini terjadi karena lubricat tidak dapat berfungsi jika temperatur minimum $150^{\circ} \mathrm{C}$.

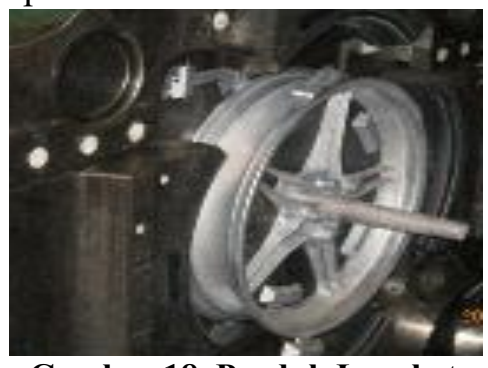

Gambar 18. Produk Lengket

2. Temperatur (b) $188^{\circ} \mathrm{C}$ produk yang dihasilkan ok tidak ada defect quality pada produk.

3. Temperatur (c) $208^{\circ} \mathrm{C}$ produk yang dihasilkan pun ok sama seperti poin b, karena temperatur maksimum yang mampu lubricant melapisi pada angka $250^{\circ} \mathrm{C}$.

4. Sementara untuk Temperatur (d) produk yang dihasilkan menjadi galling/produk seperti tercakar karena cetakan tidak terlapisi die lubricant karena mampu lubricant melapisi maksimal $250^{\circ} \mathrm{C}$. sementara pada point $\mathrm{d}$ temperatur overheat karena suhu cetakan sampai pada $316^{\circ} \mathrm{C}$.

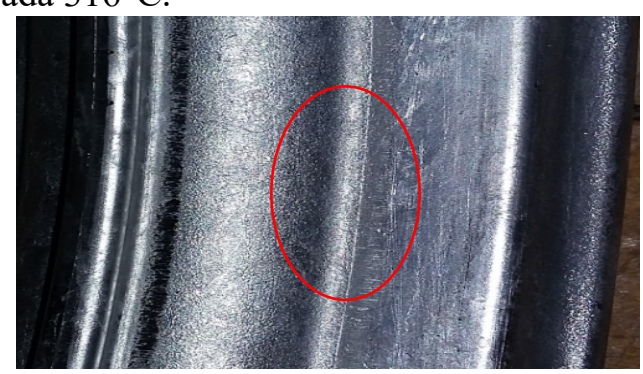

Gambar 19. Produk Galling

Temperatur yang optimal agar die lubricant dapat melapisi cetakan yaitu pada temperatur 150 $250^{\circ} \mathrm{C}$ karena jika terlalu rendah ataupun terlalu over dapat mengakibatkan die lubricant tidak dapat melapisi cetakan dengan sempurna.

Tabel 3. Monitoring Temperatur dan Lengket

\begin{tabular}{|c|c|c|c|c|c|}
\hline \multirow[b]{2}{*}{ No } & \multirow{2}{*}{$\begin{array}{l}\text { Temperatur } \\
\text { ("C) }\end{array}$} & \multirow{2}{*}{$\begin{array}{l}\text { Timer } \\
\text { cooling }\end{array}$} & \multicolumn{3}{|c|}{ Kondisi } \\
\hline & & & Lengket & $\begin{array}{l}\text { Hampir } \\
\text { lengket }\end{array}$ & Tidak lengket \\
\hline 1 & 78 & 68 & v & - & - \\
\hline 2 & 86 & 64 & $\mathrm{v}$ & - & - \\
\hline 3 & 97 & 60 & $\mathrm{v}$ & - & - \\
\hline 4 & 112 & 56 & $\mathrm{v}$ & - & - \\
\hline 5 & 135 & 52 & - & $\mathrm{v}$ & - \\
\hline 6 & 157 & 48 & - & - & $\mathrm{v}$ \\
\hline 7 & 175 & 44 & - & - & $\mathrm{v}$ \\
\hline 8 & 198 & 40 & - & - & $\mathrm{v}$ \\
\hline 9 & 213 & 36 & - & - & $\mathrm{v}$ \\
\hline 10 & 235 & 32 & - & - & $v$ \\
\hline 11 & 258 & 28 & - & v & - \\
\hline 12 & 269 & 24 & - & $\mathrm{v}$ & - \\
\hline 13 & 282 & 20 & $v$ & - & - \\
\hline 14 & 294 & 16 & $\mathrm{v}$ & - & - \\
\hline 15 & 305 & 12 & $\mathrm{v}$ & - & - \\
\hline
\end{tabular}

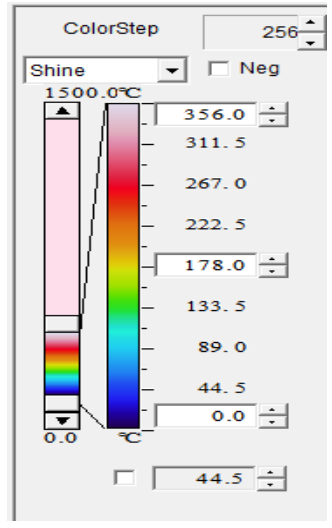

Gambar 20. Temperatur Batas Atas dan Batas Bawah

Adapun temperatur batas bawah yang dapat distandarkan yaitu pada range antara $150^{\circ} \mathrm{C}$ karena pada saat temperatur cetakan $<150^{\circ} \mathrm{C}$ cairan die lubricant tidak akan menempel karena sifat dari wax sendiri dapat melapisi jika temperatur pada suhu $>150^{\circ} \mathrm{C}$. 


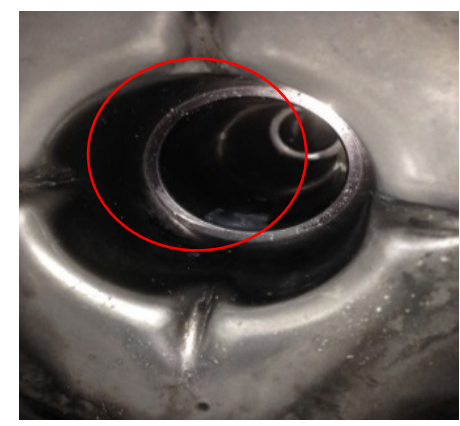

Gambar 21. Die Lubricant Tersisa karena Temperatur $<150^{\circ} \mathrm{C}$

Temperatur batas atas yaitu pada suhu $250^{\circ} \mathrm{C}$. Jika temperatur $>250^{\circ} \mathrm{C}$ die lubricant tidak bisa melapisi cetakan karena jika temperatur melebihi standar hanya akan terjadi lubricant menggumpal dan selanjutnya menguap begitu saja seperti halnya air yang ada di daun talas yang tidak akan meresap tetapi hanya akan menguap saja.

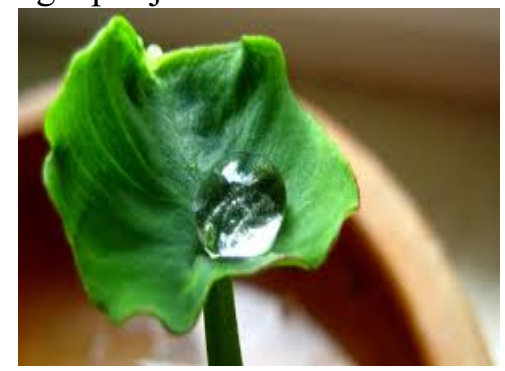

Gambar 22. Air Pada Daun Talas

Jadi jika temperatur berada pada batas bawah die lubericant tidak melapisi cetakan sehingga cetakan tidak ada lapisan film agar produk dapat release dengan sempurna dan juga dapat menimbulkan defect produk diantaranya flowline, shringkage, dan crack. Tapi jika temperatur over berada pada batas atas akan menimbulkan cairan lubricant tidak melapisi cetakan pula dan dapat menimbulkan trouble lengket, selain itu pula dapat menimbulkan defect produk berupa galling, mekure dan soldering.

\subsection{Pengaruh Lubricant Terhadap Kualitas Produk Wheel PT. XY}

Hasil kualitas produk yang ada setelah dilakukan trial agar temperatur optimum yang distandarkan akan berpengaruh terhadap kualitas dan trouble produk yang lengket pada cetakan dapat dilihat pada grafik berikut:

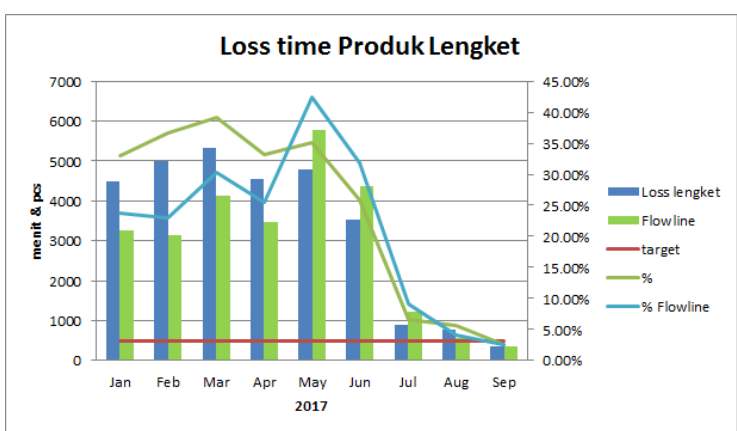

Gambar 23. Loss Time Produk lengket

\section{Temperatur $<150^{\circ} \mathrm{C}$}

Pada temperatur dibawah standar produk selain mengalami lengket pada cetakan, juga mengalami terjadinya defect produk/ cacat karena masih ada cairan lubricant tertinggal dan menimbulkan cetakan yang dingin juga tidak bisa melapisi cetakan.

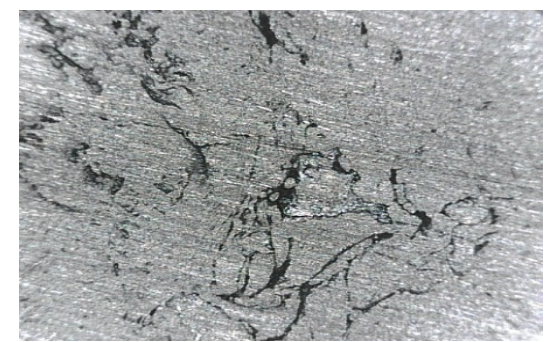

\section{Gambar 24. Produk Flowline karena Cetakan Terlalu} Dingin

2. Temperatur $150-250^{\circ} \mathrm{C}$

Pada temperatur standar didapat produk yang sempurna karena lubricant melapisi cetakan dengan sempurna.

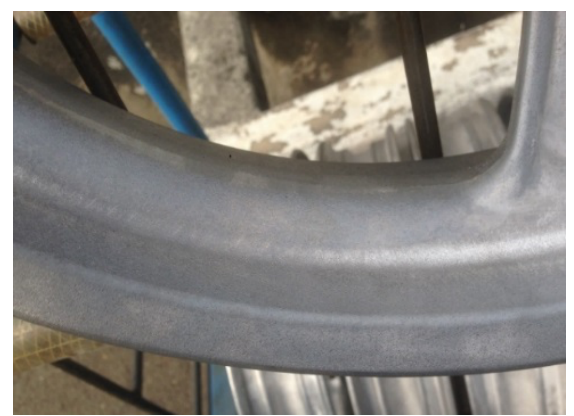

Gambar 25. Produk Ok Tanpa Defect

3. Temperatur $>250^{\circ} \mathrm{C}$

Temperatur overheat juga bisa menimbulkan produk lengket akibat cairan lubricant yang tidak bisa melapisi cetakan seperti halnya air di daun talas.

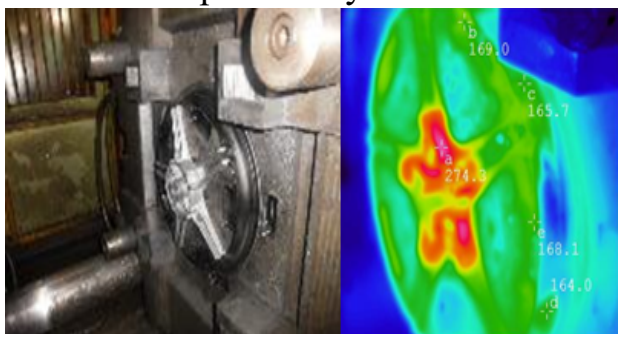

Gambar 26. Lengket karena Overheat 


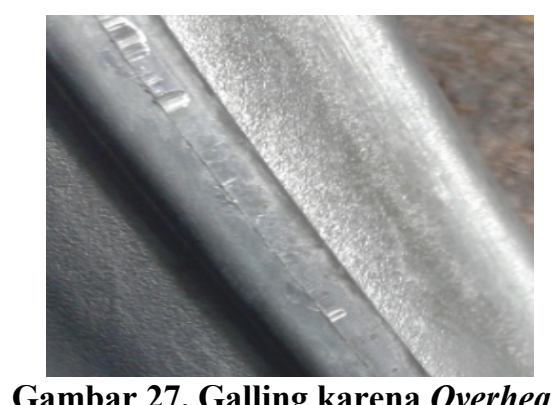

Hasil trial temperatur terhadap kualitas produk di PT. XY dapat di urutkan sesuai klasifikasi jenis reject, repair, output dan loss time sebagai berikut:

1. Reject / Quality Ratio. Dari hasil trial didapat untuk produk yang reject diantaranya:

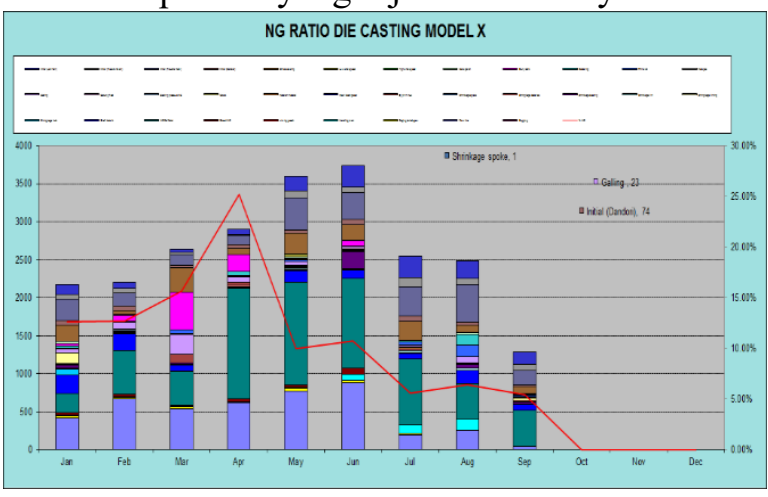

Gambar 28. Reject/Quality Ratio

Hasil percobaan trial dengan setting parameter temperatur pada bulan juni-september mengalami penurunan produk yang reject.

\section{Repair Ratio}

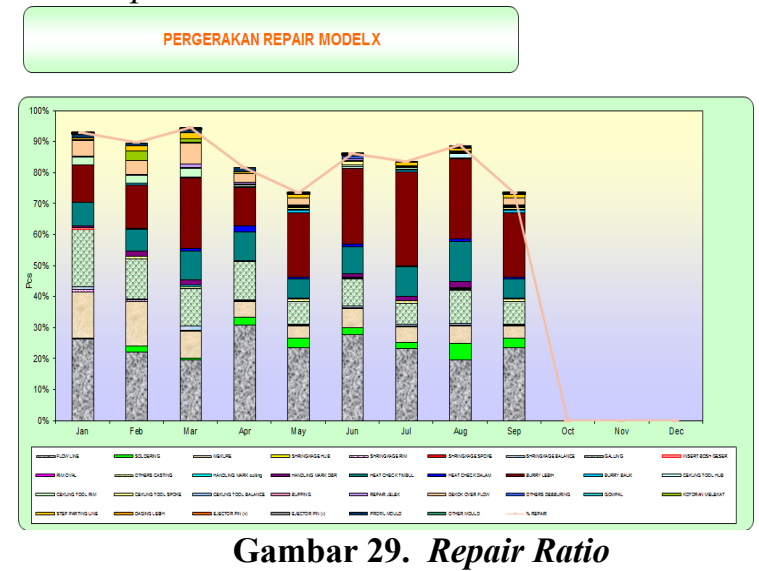

Dari Hasil percobaan produk yang di repair tidak mengalami perubahan baik itu sebelum setting temperatur dan sesudah setting parameter temperatur cetakan.

\section{Loss Time}

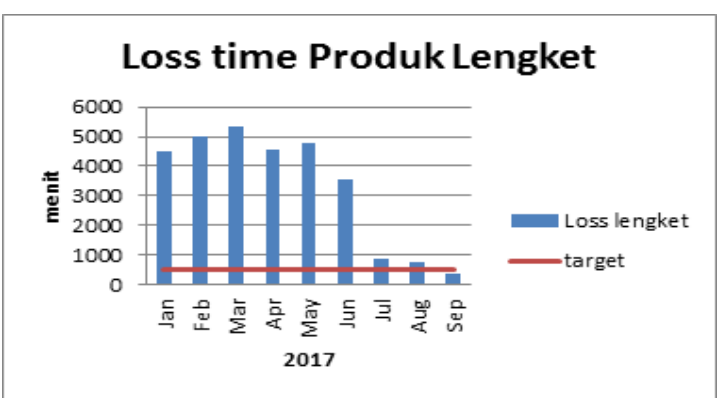

Gambar 28. Loss Time

Dari hasil eksperimen trial Loss time produk yang lengket pada cetakan menurun karena ada perubahan/monitoring temperatur cetakan agar trouble loss lengket yang diakibatkan karena cetakan yang tidak terlubrikasi mengalami penurunan yang signifikan dibanding sebelum dilakukan setting temperatur.

\section{KESIMPULAN}

\section{Temperatur optimum}

Bahwa penyebab utama dari kasus atau masalah produk lengket pada cetakan di akibatkan karena pada cetakan tidak terlapisi oleh die lubricant. Yang mana die lubricant ini akan menempel/melapisi cetakan jika temperatur cetakan memiliki tingkatan temperatur minimum dan temperatur maksimum yang telah di uji oleh penulis dimana unuk temperatur minimum di angka $150^{\circ} \mathrm{C}$, sedangkan untuk temperatur maksimum die lubricant yang mampu melapisi cetakan di angka $250^{\circ} \mathrm{C}$.

2. Temperatur batas atas $\&$ batas bawah

Alasan kenapa minimum $150^{\circ} \mathrm{C}$ temperatur yang di jadikan standar karena pada saat temperatur dibawah $<150^{\circ} \mathrm{C}$ maka seperti cipratan air bercampur die lubricant yang hanya melewati cetakan saja yang tentu tidak akan pernah melapisi cetakan hingga sempurna.

Tetapi jika temperatur maksimalpun itu tidak direkomendasikan oleh penulis karena pada saat kondisi temperatur cetakan melebihi $>250^{\circ} \mathrm{C}$ maka cairan die lubricant tidak akan menempel juga pada cetakan. Hal ini karena pada saat temperatur $>250^{\circ} \mathrm{C}$ hanya seperti air yang ada di daun talas yang tentu tidak akan pernah melapisi dan hanya akan menguap saja pada cairan die lubricant tersebut.

3. Pengaruh Lubricant terhadap kualitas

Dari data hasil pengujian didapatkan hasil untuk proses analisa temperatur yang mengethaui pengaruh temperatur terhadap ceakan dan kualitas pada wheel didapatkan hasil yang memuaskan karena 
pada saat setelah analisa dan dilakukan uji coba pada cetakan dan dilakukan monitoring maka hasil untuk masalah produk lengket pada cetakan mengalami penurunan yang signifikan karena untuk jumlah trouble lengkat pada bulan juli-september 2019 mengalami penurunan.

\section{DAFTAR PUSTAKA}

Amrullah.Irvan.2013.Atomisasi gas argon. Bandung:Politeknik Negeri Bandung

Edward J. Winarcik.2003. High Integrity Die Casting Proceses, New York USA: Jhon Wiley \& Son

Maulana.Firman.2016. Standar mold design. Indonesia:Yamaha motor

Ueda.Mr.2010.Quality die casting. Japan:Yamaha motor

http://Docplayer.info/amp/35046082-analisasimulasi-high-pressure-die-casting-hpdcaluminium-alloy-dengan-dua-variancooling-menggunakan-softwaremagma.html/

http://hapli.wordpress.com/non_ferro/aluminiumalloy/

www.jiedamould.com/id/workshop/die-castingworkshop/

www.pengaruh-lubrikasi-terhadap-cetakan-diecasting 